\title{
Kardiyoloji Polikliniğine Başvuran Hastaların Göstermiş Oldukları Hastalık Davranışlarının Belirlenmesi
}

\author{
DOI: 10.26466/opus.869338
}

$*$

\author{
Rukiye Numanoğlu * \\ *Dr. Öğr. Üyesi, Başkent Üniversitesi \\ E-Posta: numanoglu@baskent.edu.tr \\ ORCID: $\underline{0000-0001-9637-1866}$

\section{Öz}

Günümüzde etkili sağlık hizmetleri için kısıtlı kaynakların verimli şekilde ve ihtiyaçlar doğrultusunda kullanılması gerekmektedir. Hastalıklar konusunda ciddi düzeyde endişe duymak, gereksiz tıbbi yardım aramak, hekimlere gerekli olmayan tıbbi incelemeleri yapma konusunda ısrarcı olmak velveya gereksiz ilaç kullanımı yapmak anormal hastalık davranışını nitelemektedir ve anormal hastalık davranışı gösteren bireyler sağlık hizmetlerini ihtiyaçları doğrultusunda kullanmamaktadırlar. Sağlıkçalışanlarının, hastalık davranışının çeşitliliğinin bilincinde olarak hizmet sunması, hekim-hasta iletişiminin güçlendirilmesi ve sağlık hizmetlerinin etkili kullanımı konusunda bilinçlendirilmesi açısından önem arz etmektedir. Yapılan bu araştırma kişilerin gösterdikleri hastalık davranışını ve bu davranışı etkileyen sosyo-demografik özellikleri ortaya koymak amacıyla tasarlanmıştır. Araştırma kapsamına Ankara'da faaliyet gösteren üçüncü basamak bir sağllk kuruluşunun kardiyoloji polikliniğine başvuran ve araştırmaya katılmayı kabul eden 255 kişi dahil edilmiştir. Araştırmada veri toplama aracı olarak sosyo-demografik bilgi formu ve Hastalık Davranışı Değerlendirme Ölçeği'nden (HaDDÖ) oluşan soru formu kullanılmış ve yüz yüze görüşme yöntemi ile veriler toplanmıştır. Yapılan analizler sonucunda 255 katılımcıdan \%52,9'unun artmış anormal hastalık davranışı gösterdikleri belirlenmiştir. Kişilerin eăitim düzeyleri, gelir ve çalışma durumları ile artmış anormal hastalık davranışları arasında anlamlı bir ilişki olduğu sonucuna ulaşılmıştır.

Anahtar Kelimeler: Sağlık Hizmetleri Kullanımı, Hastalık Davranışı, Anormal Hastalık Davranışı 


\title{
Determination Of The Illness Behaviour Of Patients Applied Cardiology Outpatient Clinic
}

\begin{abstract}
Today, limited resources should be used efficiently and in accordance with needs for effective healthcare services. Being seriously concerned about illnesses, seeking unnecessary medical help, insisting on making unnecessary medical examinations to physicians, and / or using unnecessary medication characterize abnormal illness behavior and individuals with abnormal illness behavior do not use health services in line with their needs. It is important for healthcare professionals to provide services with the awareness of the diversity of disease behavior, to strengthen physician-patient communication and to raise awareness of the effective use of health services. This research is designed to reveal the illness behavior of individuals and the socio-demographic characteristics that affect this behavior. 255 persons who applied to the cardiology outpatient clinic of a tertiary health institution operating in Ankara and accepted to participate in the study were included in the scope of the study. Socio-demographic information form and a questionnaire consisting of the Disease Behavior Assessment Scale (HaDDÖ) were used as data collection tools in the study, and data were collected by face-to-face interview method. As a result of the analysis, it was determined that $52.9 \%$ of the 255 participants showed increased abnormal disease behavior. It has been concluded that there is a significant relationship between individuals' education levels, income and employment status and increased abnormal illness behavior.
\end{abstract}

Keywords: Disease, Illness Behavior, Abnormal Illness Behavior 


\section{Giriş}

Eski dönemlerde tek amacı hayatını devam ettirebilmek olan insanoğlu, teknolojinin gelişmesi ve yaşam süresinin uzamasıyla, zamanla kendisi ve sağlığı için hep daha fazlasını istemeye başlamıştır. Günümüzde ise sağlıklı olmak, huzurlu, başarılı ve kaliteli bir yaşam sürmek her bireyin en temel beklentisi ve ihtiyacı konumuna gelmiştir. Sağlık bu denli mühim ve değerli bir olgu iken, bireylerin bedenlerinde herhangi bir aksaklık hissettiklerinde ya da anormal bir durum ile karşılaştıklarında ne şekilde davrandığı ya da neleri hastalık olarak algılayıp, tanımladıkları, nası önlemler aldıkları kısacası hastalık karşısında gösterdikleri davranışlar araştırılması gereken bir durum olarak ortaya çıkmaktadır (Asmundson, Abramowitz, Richter, ve Whedon, 2010; Önder, 2014).

Hastalık davranışı tıpta ve psikiyatride birçok bozukluğun önemli bir türüdür. Hastalık davranışı kavramı hastanın hastalığıyla başa çıkmadaki tüm davranışları içermektedir ve ilk defa Mechanic ve Volkart (1961) tarafından tanımlanmış ve "bazı ağrıları, rahatsızlıkları veya diğer organik bozukluk belirtilerini fark eden bir birey tarafından semptomların algılanması, değerlendirilmesi ve eyleme geçilmesi" olarak ifade edilmiştir. Mechanic'e (1978) göre, hastalık davranışının içerisinde "hastalık semptomlarını algılama / yorumlama " ve " hastalik için yardım arama " olmak üzere iki ana boyut bulunmaktadır ve bu boyutlar birbirine paralel olarak ilerlemektedir. Anormal hastalık davranışı (Pilowsky, 1969) ise, hastalıkları konusunda ciddi düzeyde endişe duyan, gereksiz tıbbi yardım arayan, hekimlere gerekli olmayan tibbi incelemeleri yapma konusunda ısrarcı olan ve/veya gereksiz ilaç kullanımı yapan kişileri tanımlamakta kullanılan bir terimdir. Bunun yanında, hastalıkla geçirilen günlerin artması, fiziksel hareketliliğin kısıtlanması da anormal hastalık davranışının sonucunda ortaya çıkan durumlardır ve bu nedenle hastalık davranışı bir hastalığın toplumsal maliyetini artıran önemli bir unsur olarak ortaya çıkmaktadır.

Hastalık davranışının bilinmesi ile hastaya en uygun tedavi seçeneğinin sunulması, hastanın tıbbi tavsiyelere uyum göstermesinin sağlanması, hekim-hasta iletişiminin güçlendirilmesi mümkün olmaktadır ve tüm bunların sonucunda sağlığa ayrılan sınırlı kaynakların etkili ve verimli kullanımında önemli bir ilerleme sağlanmaktadır (Mechanic, 1995). 
Hastalık davranışının, hastalıkla ilişkili ciddi bozukluklardan çok bireylerin özelliklerine göre ortaya çıktığını gösteren birçok çalışma bulunmaktadır. Petrie ve diğerleri tarafından yapılan bir çalışmada miyokard enfarktüsü geçiren hastaların yeniden işe başlama, fonksiyonelliğini geri kazanma durumlarında hastalıkla ilgili tıbbi durumların etkisinin oldukça düşük olduğu, bireylerin hastalı̆̆ı algılayışının en önemli etken olduğu ortaya konulmuştur. Hastalığın algılanmasında ise hastalığın birey tarafından nasıl tanımlandığı, hastalığın nedenleri, ne kadar süreceği, yaratacağı sonuçlara ilişkin hastanın kişisel görüşleri ve hastanın hastalığı nasıl kontrol edeceğine ilişkin düşünceleri rol oynamaktadır (Petrie, 1996).

Kardiyovasküler hastalıklar dünya genelinde morbidite, mortalite ve ekonomik yüke neden olan en önemli hastalıklardır. Coşkun (2017) tarafından kardiyoloji polikliniğinde yapılmış olan bir araştırmada hastaların birçoğunun anormal hastalık davranışı gösterdiği, bunun ise yüksek düzeyde sağlık kaygısı ile ilişkili olduğu belirlenmiştir. Ağrı, acı veya bedensel herhangi bir aksaklık durumunda yüksek düzey sağlık kaygısı yaşayan bireyler, anormal hastalık davranışı sergilemektedirler. Özellikle yüksek düzey sağlık kaygısı taşıyan bireylerin kardiyoloji polikliniğine başvurma eğilimleri olduğu, bunun yanında yoğun sağlık kaygısının kardiyovasküler hastalıkları tetiklediği de ortaya konulmuştur.

\section{Yöntem}

\section{Araştırmanın Amacı ve Önemi}

Toplumdan topluma bireylerin karşılaştıkları sağlık sorunları ve bu sorunlar karşısında göstermiş oldukları hastalık davranışı farklılık göstermektedir. Bu çalışmanın amacl; bireylerin gösterdikleri hastalık davranışını ve bu davranışı etkileyen sosyo-demografik özellikleri belirlemektir. Bireylerin göstermiş oldukları hastalık davranışı sağlık hizmetleri kullanım oranlarını önemli ölçüde etkilemektedir. Anormal hastalık davranışı ile ilişkilendirilen bazı psikolojik rahatsızlıklar (sağlık kaygısı, kaygı bozukluğu, panik atak vs.) kardiyovasküler hastalıkları tetiklemekte ve buna bağlı olarak kardiyoloji polikliniğine yapılan başvuruları da artırmaktadır. Sağlıkları ile ilgili fazla kaygı duyan bu kişiler, gereksiz yere sağlık kurumlarını kullanmaktadır. Hastalık davranışı konusunda çalışma yapılması; sağlık hizmetlerinde kısıtlı olan kaynakların verimli ve ihtiyaçlarla doğru orantılı olarak kullanılması, bireylerin 
farkındalığının artırılarak bilinçli kullanmaya teşvik edilmesi açısından önem arz etmektedir. Ayrıca, Türkiye'de hastalık davranışı konusunda yapılan çok fazla çalışma bulunmamaktadır.

\section{Evren ve Örneklem}

Araştırma tanımlayıcı türde kesitsel bir saha araştırması olarak planlanmıştır. Araştırmanın örneklemini, Ankara'da üçüncü basamak bir sağlık kuruluşunun (erişkin) kardiyoloji polikliniğine 18.03.2019-12.04.2019 tarihleri arasında başvuran, kolayda örnekleme yöntemi ile seçilen ve araştırmaya katılmayı kabul eden 18 yaş ve üzeri 255 kişi oluşturmuştur.

\section{Veri Toplama Araçlan}

Araştırma verileri araştırmacı tarafından hazırlanan soru formu ile yüz yüze toplanmıştır. Hazırlanan soru formu 2 kısımdan oluşmaktadır. İlk kısımda bireylerin sosyo-demografik özellikleri ve sağlık durumları ile ilgili bilgileri içeren 13 soru yer almaktadır. İkinci bölümde ise Rief, Ihle, ve Pilger (2003) tarafından geliştirilen, Güleç (2012) tarafından Türkçe geçerlilik ve güvenilirlik çalışması yapılan Hastalık Davranışını Değerlendirme Ölçeği (HaDDÖ) [Scale for the Assessment of Illness Behaviour (SAIB)] kullanılmıştır. Ölçeğin Türkçe geçerlilik ve güvenilirlik çalışmasında toplam puan test-tekrar test tutarlılı̆̆ 1 (r: 0,68), ölçeğin iç tutarlılık incelenmesinde Cronbach alfa değeri 0,81 olarak hesaplanmıştır. HaDDÖ 25 soru ve "tanının doğrulanması" (2,3,4,5, $13,19,20$. maddeler), "şikayetlerin ifadesi" (6, 7, 8, 9, 10, 18. maddeler), "tedavi" $(12,14,15,17,21$. Maddeler) ve "tarama" $(1,11,16,22,23,24,25$. maddeler) olmak üzere 4 boyuttan oluşmaktadır. Ölçek Likert ölçeğine göre 0-3 arası puanlanmaktadır (0=Tamamiyla Doğru, 1=Kısmen Doğru, 2=Kısmen Doğru Değil, 3=Tamamıyla Doğru Değil). Düşük puanlar artmış hastalık davranışını ve yüksek puanlar azalmış hastalık davranışını işaret etmektedir.

Veriler SPSS 20.0 paket programına girilerek öncelikle ölçek için Cronbach alfa değeri hesaplanmıştır. Yapılan bu araştırma kapsamında ölçeğin Croncach alfa değeri 0,87 olarak hesaplanmıştır. Daha sonra tanımlayıcı istatistikler elde edilmiş, ardından ölçek puanlarının normal dağılım gösterdiği belirlenerek, ikili gruplar arasındaki ortalamaların karşılaştırılmasında Bağımız İki Örneklem T Testi, ikiden fazla grup arasındaki ortalamaların karşılaştırılmasında Tek Yönlü Varyans Analizi (ANOVA) kullanılmıştır. Tek Yönlü 
Varyans Analizi kullanılarak istatistiksel açıdan anlamlı farklılık olduğu belirlenen gruplarda farklılığın hangi gruptan kaynaklandığını belirlemeye yönelik olarak post-hoc testler gerçekleştirilmiştir.

Bu araştırma Başkent Üniversitesi Tıp ve Sağlık Bilimleri Araştırma Kurulu tarafından onaylanmış (Proje no: KA19/88) ve Başkent Üniversitesi Araştırma Fonunca desteklenmiştir.

\section{Bulgular}

Araştırmaya dahil edilen katılımcıların sosyo-demografik özelliklerine göre dağılımı Tablo 1'de verilmektedir. Katılımcıların \%54,1'inin kadın, \%45,1'inin 40-64 yaş arasında, \%82,7'sinin evli, \%59,6'sının çalışmıor, \%40,8'inin önlisans/lisans mezunu, \%46,3'ünün 2001-4000ть arasında gelir düzeyine sahip ve $\% 98,0^{\prime}$ ının sosyal güvencesi olduğu belirlenmiştir.

Tablo 1. Katılımcıların Sosyo-Demografik Özelliklerine göre Dağılımı

\begin{tabular}{|c|c|c|c|c|c|}
\hline & $\mathbf{n}$ & $\%$ & & $\mathbf{n}$ & $\%$ \\
\hline Cinsiyet & & & Eğitim Düzeyi & & \\
\hline Kadın & 138 & 54,1 & Okur-yazar değil & 3 & 1,2 \\
\hline \multirow[t]{2}{*}{ Erkek } & 117 & 45,9 & İlköğretim & 56 & 22,0 \\
\hline & & & Lise & 74 & 29,0 \\
\hline Yaş Gruplanı & & & Önlisans/Lisans & 104 & 40,8 \\
\hline $18-39$ yaş & 65 & 25,5 & Yüksek Lisans/Doktora & 18 & 7,1 \\
\hline 40-64 yaş & 115 & 45,1 & & & \\
\hline \multirow[t]{2}{*}{65 yaş ve üstü } & 75 & 29,4 & Gelir Düzeyleri & & \\
\hline & & & 2000 TL ve Alt1 & 57 & 22,4 \\
\hline Medeni Durum & & & $2001-4000 \mathrm{TL}$ & 118 & 46,3 \\
\hline Evli & 211 & 82,7 & $4001-6000 \mathrm{TL}$ & 45 & 17,6 \\
\hline Ayrı Yaşıyor/ Boşanmış & 15 & 5,9 & $6001-8000 \mathrm{TL}$ & 18 & 7,1 \\
\hline Bekâr & 29 & 11,4 & 8001 TL ve Üstü & 17 & 6,7 \\
\hline Çalışma Durumu & & & Sosyal Güvence & & \\
\hline Çalışıyor & 103 & 40,4 & Var & 250 & 98,0 \\
\hline Çalışmıyor & 152 & 59,6 & Yok & 5 & 2,0 \\
\hline
\end{tabular}

Tablo 2'de katılımcıların sağlık durumlarına göre değerlendirmeleri yer almaktadır. \%62,7' si daha önce bir ameliyat geçirdiğini, \% 18,4'ü psikiyatrik bir tanı aldığını, \%62,4'ü kronik bir hastalığı bulunduğunu ve \%66,7'si düzenli ilaç kullandığını belirtmiştir. 
Tablo 2. Katılımcıların Sağlık Durumlarına göre Dağılımları

\begin{tabular}{|c|c|c|c|c|c|}
\hline & $\mathbf{N}$ & $\%$ & & $\mathbf{N}$ & $\%$ \\
\hline \multicolumn{3}{|c|}{ Ameliyat Olma Durumları } & \multicolumn{3}{|c|}{ Kronik Hastalık Bulunma Durumu } \\
\hline Evet & 160 & 62,7 & Evet & 159 & 62,4 \\
\hline Hayır & 95 & 37,3 & Hayır & 96 & 37,6 \\
\hline \multicolumn{3}{|c|}{ Psikiyatrik Tanı Alma Durumları } & \multicolumn{3}{|c|}{ Düzenli İlaç Kullanım Durumları } \\
\hline Evet & 47 & 18,4 & Evet & 170 & 66,7 \\
\hline Hayır & 208 & 81,6 & Hayır & 85 & 33,3 \\
\hline
\end{tabular}

Katılımcların ölçek alt boyut ve toplam ölçek puanlarının otalamalarına ilişkin bilgiler Tablo 3'te yer almaktadır. Toplam ölçek puan ortalaması 35,24 (SS: 12,87) olarak hesaplanmıştır. Bu ortalamanın altında kalanlar artmış anormal hastalık davranışını işaret ederken, üzerinde yer alanlar ise azalmış anormal hastalık davranışını temsil etmektedir. Ölçek puanının alt boyutlarından en yüksek ortalama puanı 9,76 ile tarama boyutu almıştır. Tanının doğrulanması boyutunun puan ortalaması 5,58 ile en düşük puan ortalamasinı almıştır.

Tablo 3.Katılımcılarn Toplam Ölçek Puan ve Alt Boyutlarının Puan Ortalamaları

\begin{tabular}{lllll}
\hline & Min. & Maks. & Ortalama & S.S. \\
\hline Tanının Doğrulanması &, 00 & 14,00 & 5,58 & 3,36 \\
Tarama &, 00 & 21,00 & 9,76 & 4,69 \\
Şikayetlerin İfadesi &, 00 & 18,00 & 8,82 & 4,26 \\
Tedavi &, 00 & 15,00 & 8,05 & 3,20 \\
Toplam Puan & 0 & 65 & 35,24 & 12,87 \\
\hline
\end{tabular}

Tablo 4 incelendiğinde toplam ölçek puan ortalamalarına göre katılımc1ların \%52,9'unun artmış anormal hastalık davranışı göstermiş olduğu belirlenmiştir. Tanının doğrulanması boyutuna göre katılımcıların \%51,4'ünün, tarama boyutuna göre $\% 47,8$ inin, şikayetlerin ifadesi boyutuna göre $\% 47,5^{\prime}$ inin, tedavi boyutuna göre $\% 54,5^{\prime}$ inin artmış anormal hastalık davranışı gösterdiği belirlenmiştir.

Tablo 4. Katılımcılarm Anormal Hastalık Davranışı Gösterme Durumlarna İlişkin Dağllim

\begin{tabular}{lllll}
\hline & \multicolumn{2}{l}{ Artmış Anormal Hastalık Davranışı } & Azalmış Anormal Hastalık Davranışı \\
\hline & $\mathbf{n}$ & $\mathbf{\%}$ & $\mathbf{n}$ & $\mathbf{\%}$ \\
Tanının Doğrulanması & 131 & 51,4 & 124 & 48,6 \\
Tarama & 122 & 47,8 & 133 & 52,2 \\
Şikâyetlerin İfadesi & 121 & 47,5 & 134 & 52,5 \\
Tedavi & 139 & 54,5 & 116 & 45,5 \\
Toplam Ölçek Puan & 135 & 52,9 & 120 & 47,1 \\
\hline
\end{tabular}


HaDDÖ puanları ile sosyo-demografik faktörler ve sağlık durumuna ilişkin değişkenler arasında ki ilişkinin incelenmesinde cinsiyet, çalışma durumu, sosyal güvence, ameliyat geçirme, kronik hastalık bulunma durumu, psikiyatrik tanı alma ve düzenli ilaç kullanımı değişkenleri için Bağımız İki Örneklem T Testi, yaş, medeni durum, eğitim ve gelir düzeyi değişkenleri için Tek Yönlü Varyans Analizi (ANOVA) kullanılmıştır. Yaş gruplarına, cinsiyete, medeni duruma, sosyal güvence durumuna, ameliyat geçirme durumuna, kronik hastalık bulunma durumuna, psikiyatrik tanı alma ve düzenli ilaç kullanma durumlarına göre ölçek puan ortalamalarının istatistiksel açıdan anlamlı farklılık göstermediği ( $p>0,05)$ belirlenmiştir (Tablo 5).

Katılımcların eğitim düzeyine göre şikayetlerin ifadesi ve tedavi alt boyut ölçek puan ortalamaları ile toplam ölçek puan ortalamalarının istatistiksel açıdan anlamlı farklılık gösterdiği belirlenmiştir $(p<0,05)$. Ortalamalar arasındaki farklılığın hangi gruplardan kaynaklandığını belirlemek amacıyla öncelikle varyansların homojenliği test edilmiş, varyansların homojen olduğu belirlenerek post-hoc testlerden Bonferroni testi uygulanmış ve şikayetlerin ifadesi, tedavi alt boyutu ölçek puan ortalamaları ile toplam ölçek puan ortalamalarında lise ve altı eğitim düzeyine sahip olan bireyler ile lisans ve üstü eğitim düzeyine sahip olan bireylerin ortalamalarının istatistiksel açıdan anlamlı farklılık gösterdiği belirlenmiştir. Buna göre, lise ve altı eğitim düzeyine sahip olan bireylerin artmış anormal hastalık davranışı gösterdiğini söylemek mümkündür.

Katılımcıların gelir düzeyine göre toplam ölçek puan ortalamalarının istatistiksel açıdan anlamlı farklılık gösterdiği belirlenmiş $(p<0,05)$, ortalamalar arasındaki farklılığın hangi gruplardan kaynaklandığını belirlemek amacıyla varyansların homojen olması nedeniyle Bonferroni testi uygulanmış ve 4000TL ve altı gelir düzeyine sahip bireyler ile 6001TL ve üstü gelir düzeyine sahip olan bireylerin ortalamalarının istatistiksel açıdan anlamlı farklılık gösterdiği belirlenmiştir. Buna göre, gelir düzeyi düştükçe bireylerin artmış anormal hastalık davranışı gösterme eğiliminin arttı̆̆ını söylemek mümkündür.

Katılımcıların çalışma durumlarına göre şikayetlerin ifadesi ve tedavi alt boyut ölçek puan ortalamaları ile toplam ölçek puan ortalamalarının istatistiksel açıdan anlamlı farklılık gösterdiği belirlenmiştir $(p<0,05)$. Çalışan bireylerin ölçek puan ortalamalarının çalışmayan bireylere kıyasla daha yüksek 
olduğu belirlenmiştir. Buna göre, çalışmayan bireylerin çalışan bireylere kıyasla artmış anormal hastalık davranışı gösterme eğiliminin yüksek olduğu söylenebilir.

Tablo 5. Katılımcılarn Sosyo-Demografik Özelliklerine ve Sağlık Durumlarna göre Toplam Ölçek Puan ve Alt Boyutlarnın Puan Ortalamalar

\begin{tabular}{|c|c|c|c|c|c|c|c|c|c|c|}
\hline & \multicolumn{2}{|c|}{$\begin{array}{l}\text { Tanının } \\
\text { Doğrulanması }\end{array}$} & \multicolumn{2}{|c|}{ Tarama } & \multicolumn{2}{|c|}{$\begin{array}{l}\text { Şikâyetlerin } \\
\text { İfadesi }\end{array}$} & \multicolumn{2}{|l|}{ Tedavi } & \multicolumn{2}{|c|}{$\begin{array}{l}\text { Toplam } \\
\text { Ölçek Puanı }\end{array}$} \\
\hline & Ort. & SS & Ort. & SS & Ort. & SS & Ort. & SS & Ort. & SS \\
\hline \multicolumn{11}{|l|}{ Yaş } \\
\hline $18-39$ yaş & 5,65 & 3,35 & 9,43 & 4,63 & 8,72 & 4,27 & 8,28 & 3,08 & 34,94 & 12,03 \\
\hline 40-64 yaş & 5,53 & 3,39 & 10,33 & 4,79 & 9,47 & 4,22 & 8,49 & 3,30 & 36,97 & 13,17 \\
\hline \multirow[t]{3}{*}{65 yaş ve üstü } & 5,63 & 3,39 & 9,20 & 4,56 & 7,92 & 4,19 & 7,20 & 3,02 & 32,84 & 12,87 \\
\hline & \multicolumn{2}{|l|}{$\mathrm{F}=, 031$} & \multicolumn{2}{|l|}{$\mathrm{F}=1,549$} & \multicolumn{2}{|c|}{$\mathrm{F}=2,076$} & \multicolumn{2}{|l|}{$\mathrm{F}=2,968$} & \multicolumn{2}{|c|}{$\mathrm{F}=2,380$} \\
\hline & \multicolumn{2}{|l|}{$\mathrm{p}=, 969$} & \multicolumn{2}{|l|}{$\mathrm{p}=, 215$} & \multicolumn{2}{|c|}{$\mathrm{p}=, 078$} & \multicolumn{2}{|l|}{$p=, 060$} & \multicolumn{2}{|l|}{$\mathrm{p}=, 095$} \\
\hline \multicolumn{11}{|l|}{ Cinsiyet } \\
\hline Kadın & 5,31 & 3,15 & 9,53 & 4,53 & 8,35 & 4,05 & 7,91 & 3,10 & 33,94 & 12,17 \\
\hline \multirow[t]{3}{*}{ Erkek } & 5,91 & 3,58 & 10,05 & 4,89 & 9,38 & 4,45 & 8,22 & 3,32 & 36,76 & 13,54 \\
\hline & \multicolumn{2}{|l|}{$t=-1,429$} & \multicolumn{2}{|l|}{$t=-, 885$} & \multicolumn{2}{|c|}{$\mathrm{t}=-1,947$} & \multicolumn{2}{|l|}{$t=-, 768$} & \multicolumn{2}{|c|}{$\mathrm{t}=-1,750$} \\
\hline & $\mathrm{p}=, 154$ & & $\mathrm{p}=, 377$ & & $\mathrm{p}=, 053$ & & $\mathrm{p}=, 443$ & & $\mathrm{p}=, 081$ & \\
\hline Medeni Durum & & & & & & & & & & \\
\hline Evli & 5,52 & 3,45 & 9,75 & 4,83 & 8,61 & 4,29 & 7,90 & 3,28 & 34,74 & 13,42 \\
\hline $\begin{array}{l}\text { Ayrı Yaşıyor/ } \\
\text { Boşanmış }\end{array}$ & 5,93 & 2,84 & 10,80 & 4,49 & 9,60 & 4,50 & 8,60 & 2,82 & 38,07 & 10,25 \\
\hline Bekâr & 5,90 & 3,03 & 9,34 & 3,80 & 10,00 & 3,80 & 8,93 & 2,70 & 37,34 & 9,48 \\
\hline & $\mathrm{F}=, 241$ & & $\mathrm{~F}=, 479$ & & $\mathrm{~F}=1,63$ & & $\mathrm{~F}=1,571$ & & $\mathrm{~F}=, 905$ & \\
\hline & $\mathrm{p}=, 786$ & & $\mathrm{p}=, 620$ & & $\mathrm{p}=, 197$ & & $\mathrm{p}=, 210$ & & $\mathrm{p}=, 406$ & \\
\hline Ĕ̆itim Düzeyi & & & & & & & & & & \\
\hline Lise ve altı & 5,08 & 3,31 & 9,11 & 4,53 & 7,59 & 3,91 & 7,50 & 3,03 & 32,17 & 11,77 \\
\hline Önlisans & 6,30 & 3,84 & 10,19 & 4,85 & 9,22 & 4,31 & 8,81 & 3,82 & 38,07 & 14,87 \\
\hline Lisans ve üstü & 6,11 & 3,22 & 10,57 & 4,79 & 10,44 & 4,19 & 8,61 & 3,14 & 38,72 & 12,81 \\
\hline & $\mathrm{F}=3,325$ & & $\mathrm{~F}=2,823$ & & $\mathrm{~F}=13,8$ & & $\mathrm{~F}=4,270$ & & $F=8,352$ & \\
\hline & $\mathrm{p}=, 038$ & & $\mathrm{p}=, 061$ & & $\mathrm{p}=, 000$ & & $\mathrm{p}=, 015$ & & $\mathrm{p}=, 000$ & \\
\hline Gelir Düzeyleri & & & & & & & & & & \\
\hline 4000 TL ve Altı & 5,53 & 3,45 & 9,49 & 4,45 & 8,52 & 4,12 & 7,97 & 3,16 & 34,34 & 12,60 \\
\hline $4001-6000 \mathrm{TL}$ & 5,09 & 3,27 & 9,20 & 4,56 & 8,71 & 4,01 & 8,29 & 3,46 & 34,69 & 12,74 \\
\hline 6001 TL ve Üstü & 6,54 & 2,93 & 11,91 & 5,54 & 10,49 & 4,98 & 8,20 & 3,13 & 40,40 & 13,53 \\
\hline & $\mathrm{F}=1,494$ & & $\mathrm{~F}=2,420$ & & $\mathrm{~F}=2,17$ & & $\mathrm{~F}=, 223$ & & $\mathrm{~F}=3,339$ & \\
\hline & $\mathrm{p}=, 145$ & & $\mathrm{p}=, 113$ & & $\mathrm{p}=, 143$ & & $\mathrm{p}=, 801$ & & $\mathrm{p}=, 037$ & \\
\hline Çalışma Durun & & & & & & & & & & \\
\hline Evet & 5,92 & 3,33 & 10,17 & 4,64 & 9,65 & 4,13 & 8,60 & 3,28 & 37,46 & 12,53 \\
\hline Hayır & 5,36 & 3,38 & 9,49 & 4,73 & 8,26 & 4,27 & 7,68 & 3,10 & 33,73 & 12,92 \\
\hline & $t=1,307$ & & $\mathrm{t}=1,138$ & & $t=2,58 c$ & & $t=2,264$ & & $t=2,287$ & \\
\hline & $\mathrm{p}=, 192$ & & $\mathrm{p}=, 256$ & & $\mathrm{p}=, 010$ & & $\mathrm{p}=, 024$ & & $\mathrm{p}=, 023$ & \\
\hline Sosyal Güvence & & & & & & & & & & \\
\hline Var & 5,57 & 3,39 & 9,76 & 4,72 & 8,84 & 4,28 & 8,05 & 3,20 & 35,22 & 12,94 \\
\hline Yok & 6,40 & 1,52 & 10,00 & 3,81 & 8,20 & 3,49 & 8,40 & 3,78 & 36,20 & 9,42 \\
\hline
\end{tabular}




\begin{tabular}{|c|c|c|c|c|c|c|c|c|c|c|}
\hline & \multirow{2}{*}{\multicolumn{2}{|c|}{$\begin{array}{l}\mathrm{t}=-, 544 \\
\mathrm{p}=, 587\end{array}$}} & \multicolumn{2}{|l|}{$t=-, 111$} & \multicolumn{2}{|l|}{$t=, 330$} & \multicolumn{2}{|l|}{$t=-, 243$} & \multicolumn{2}{|l|}{$t=-, 169$} \\
\hline & & & \multicolumn{2}{|l|}{$\mathrm{p}=, 912$} & \multicolumn{2}{|l|}{$\mathrm{p}=, 742$} & \multicolumn{2}{|l|}{$\mathrm{p}=, 808$} & \multicolumn{2}{|l|}{$\mathrm{p}=, 866$} \\
\hline \multicolumn{11}{|c|}{ Ameliyat olma durumlarn } \\
\hline Evet & 5,43 & 3,28 & 9,73 & 4,77 & 8,71 & 4,29 & 7,92 & 2,98 & 34,79 & 12,37 \\
\hline \multirow[t]{3}{*}{ Hayır } & 5,86 & 3,50 & 9,83 & 4,59 & 9,01 & 4,22 & 8,28 & 3,55 & 35,98 & 13,70 \\
\hline & $\mathrm{t}=-1,005$ & & $\mathrm{t}=-, 165$ & & $t=-, 539$ & & $t=-, 881$ & & $\mathrm{t}=-, 710$ & \\
\hline & $\mathrm{p}=, 316$ & & $\mathrm{p}=, 869$ & & $\mathrm{p}=, 590$ & & $\mathrm{p}=, 379$ & & $\mathrm{p}=, 478$ & \\
\hline \multicolumn{11}{|c|}{ Kronik Hastalık Bulunma Durumu } \\
\hline Evet & 5,67 & 3,41 & 10,02 & 4,65 & 8,77 & 4,11 & 7,79 & 3,04 & 35,28 & 12,50 \\
\hline \multirow[t]{3}{*}{ Hayır } & 5,46 & 3,30 & 9,35 & 4,77 & 8,92 & 4,53 & 8,49 & 3,42 & 35,16 & 13,53 \\
\hline & $\mathrm{t}=, 478$ & & $\mathrm{t}=1,096$ & & $t=-, 271$ & & $t=-1,691$ & $\mathrm{p}=$ & $\mathrm{t}=, 076$ & \\
\hline & $\mathrm{p}=, 633$ & & $\mathrm{p}=, 274$ & & $\mathrm{p}=, 787$ & & ,092 & & $\mathrm{p}=, 939$ & \\
\hline \multicolumn{11}{|c|}{ Psikiyatrik Tan Alma Durumlan } \\
\hline Evet & 6,36 & 3,71 & 9,77 & 4,30 & 8,57 & 3,69 & 7,60 & 3,32 & 35,51 & 13,12 \\
\hline \multirow[t]{3}{*}{ Hayır } & 5,41 & 3,26 & 9,77 & 4,79 & 8,88 & 4,38 & 8,16 & 3,17 & 35,17 & 12,85 \\
\hline & $\mathrm{t}=1,752$ & & $\mathrm{t}=-, 004$ & & $\mathrm{t}=-, 443$ & & $\mathrm{t}=-1,089$ & & 160 & $n=8$ \\
\hline & $\mathrm{p}=, 081$ & & $\mathrm{p}=, 997$ & & $\mathrm{p}=, 658$ & & $\mathrm{p}=, 277$ & & 162 & $=, 8 / 1$ \\
\hline \multicolumn{11}{|c|}{ Düzenli İlaç Kullanım Durumlan } \\
\hline Evet & 5,66 & 3,49 & 9,92 & 4,83 & 8,46 & 4,13 & 7,68 & 3,07 & 34,79 & 12,71 \\
\hline \multirow[t]{3}{*}{ Hayır } & 5,45 & 3,12 & 9,46 & 4,43 & 9,54 & 4,45 & 8,80 & 3,35 & 36,12 & 13,22 \\
\hline & $\mathrm{t}=, 473$ & & & & $\mathrm{t}=-1,91$ & & $\mathrm{t}=-, 659$ & & $\mathrm{t}=-, 773$ & \\
\hline & $\mathrm{p}=, 637$ & & & $\mathrm{p}=, \mathrm{s}$ & $\mathrm{p}=, 057$ & & $\mathrm{p}=, 508$ & & $\mathrm{p}=, 440$ & \\
\hline
\end{tabular}

\section{Tartışma ve Sonuç}

Bireylerin göstermiş oldukları hastalık davranışı, sağlık hizmetleri kullanımlarını doğrudan veya dolaylı olarak etkilemektedir. Yapılan bu araştırmada yaş gruplarına, cinsiyete, medeni duruma, sosyal güvence durumuna, ameliyat geçirme durumuna, kronik hastalık bulunma durumuna, psikiyatrik tanı alma ve düzenli ilaç kullanma durumlarına göre ölçek puan ortalamalarının istatistiksel açıdan anlamlı farklılık göstermediği $(p>0,05)$, çalışma durumuna, gelir düzeyine ve eğitim düzeyine göre toplam ölçek puan ortalamalarının istatistiksel açıdan anlamlı farklılık gösterdiği belirlenmiştir $(\mathrm{p}<0,05)$.

Araştırmada elde edilen sonuçlar literatürle benzerlik göstermektedir. Ancak bunun yanında, Yılmaz (2017) tarafından yapılan bir araştırmada, cinsiyetin hastalık davranışı üzerinde etkili olduğu, kadınların sağlık kaygısının ve bunun sonucunda artmış anormal hastalık davranışının erkeklere kıyasla daha yüksek olduğu ortaya konulmuştur.

Araştırmada psikiyatrik tanısı olduğunu belirten katılımcı sayısı oldukça düşüktür ve yapılan analizlerde gözlem sayısının düşük olması nedeniyle anlamlı bir ilişki tespit edilememiştir. Literatür incelendiğinde, bireylerin kaygı 
seviyeleri artıkça anormal hastalık davranışının arttığı ve buna bağlı olarak yaşam kalitesinin düştüğü ortaya konulmuştur (Y1lmaz, 2017). Yoğun kayg1 içerisinde olan bireylerin bu durumla mücadele edebilmek adına gereksiz yere sağlık kurumlarına kontrole gitmeleri, farklı hekim arayışlarına girmeleri, sürekli bedenlerinde bir aksaklık olup olmadığını kontrol etmeleri ve ettirmeleri ve değişik tedavi yöntemleri talebinde olmaları beklenen durumlar olarak ortaya çıkmaktadır.

Araştırma sonucunda eğitim ve gelir düzeyi düştükçe, artmış anormal hastalık davranışının daha fazla görüldüğ̈ü sonucu elde edilmiştir. Bu sonuç beklenen ve literatürle uyumlu bir bulgudur. Literatür incelendiğinde Young (2004) tarafından yapılan bir çalışmada eğitim seviyesi artıkça, kişilerin daha bilinçli sağlık hizmetleri kullandıklarını ve hastalık davranışını yönetmeye ilişkin daha fazla güce sahip oldukları ortaya konulmuştur. Bu bağlamda eğitim seviyesi yüksek bireylerin anormal hastalık davranışı gösterme eğilimlerinin azalacağı ve sağlık hizmetlerini daha bilinçli bir şekilde kullanacağı söylenilebilir. Sağlık okuryazarlı̆̆ı ve sağlık eğitiminin yükselmesi ile bireylerin sağlık bilinci yükselecek ve böylece sağlık hizmetlerinin ihtiyaçlar doğrultusunda kullanımı konusunda farkındalık artacaktır.

Araştırmada çalışmayan bireylerin daha fazla artmış anormal hastalık davranışı gösterdiği belirlenmiştir. Bu bağlamda bireylerin çalışma hayatına dâhil olmadıklarında daha fazla artmış anormal hastalık davranışı gösterdikleri görülmüştür. Bilindiği üzere çalışma hayatının insan hayatında vitamin etkisi vardır. Bireylerin çalışma hayatına daha fazla dâhil olması dolaylı olarak hastalık karşısında gösterdiği davranışını da etkileyecektir.

Eğitim; bireylerin çalışma durumlarını, ekonomik koşullarını etkilediği gibi sağlık davranışını ve sağlık hizmeti kullanma eğilimlerini şekillendirir. İyi eğitimli insanların işsiz olma olasılıkları daha düşüktür (Ross, 1995). Ülkemizde ortalama yaşam süresinin giderek uzaması ile yaşlı nüfus oranı giderek artmaktadır. Yaşlı nüfus oranı artıkça her ülkede aktif yaşlanma politikaları geliştirilmeye başlanmıştır. Bunun temel sebebi aslında kişileri yaşlandıran durumun "yaş" değil, "yaş" aldıkça çalışma hayatından erken dönemde ellerinin çekilmesidir. Sosyal politikalar oluşturulurken aktif yaşlanmayla ilgili çalışmaların desteklenmesi ve yaşlı nüfusa çalışma hayatında daha fazla yer verecek politikaların geliştirilmesi gerekmektedir (Çolak ve Özer 2015). 


\title{
EXTENDED ABSTRACT
}

\section{Determination Of The Illness Behaviour Of Patients Applied Cardiology Outpatient Clinic}

\author{
Rukiye Numanoğlu \\ Başkent University
}

Today, limited resources should be used efficiently and in accordance with needs for effective healthcare services. Being seriously concerned about illnesses, seeking unnecessary medical help, insisting on making unnecessary medical examinations to physicians, and / or using unnecessary medication characterize abnormal illness behavior and individuals with abnormal illness behavior do not use health services in line with their needs. There are many studies shows that illness behavior emerges according to the characteristics of the individuals rather than serious disorders related to the illness and it has been demonstrated that especially individuals' perception of illness is the most important factor. It is important for healthcare professionals to provide services with the awareness of the diversity of disease behavior, to strengthen physician-patient communication and to raise awareness of the effective use of health services. This research is designed to reveal the illness behavior of individuals and the socio-demographic characteristics that affect this behavior. The research was planned as a descriptive cross-sectional field study. 255 persons who applied to the cardiology outpatient clinic of a tertiary health institution operating in Ankara and accepted to participate in the study were included in the scope of the study. The research data were collected face to face with the questionnaire. The questionnaire was prepared by the researcher and consists of 2 parts. In the first part, there are 13 questions containing information about individuals' socio-demographic characteristics and health conditions. In the second part, the Scale for the Assessment of Illness Behavior (SAIB), developed by Rief, Ihle, and Pilger (2003), was used. The Turkish validity and reliability of the scale was conducted by Güleç (2012). This scale included 25 items and comprised five sub-dimensions: verification of diagnoses, expression of symptoms, medication, consequences of illness, 
and scanning. The items are rated on a four-point Likert Scale: "I agree completely-I partially agree-I partially disagree-I disagree completely," which is scored from 0 to 3 . Lower scores indicate increased illness behaviour and higher scores indicate less illness behaviour. Firstly, by entering the data into the SPSS 20.0 program, descriptive statistics were obtained. Afterwards, it was determined that the scale scores showed a normal distribution, the Independent Sample T Test was used to compare the means of two independent groups. One-Way ANOVA was used to compare the means of more than two independent groups and post-hoc tests are used for to determine where the differences truly came from. It was determined that, $54.1 \%$ of the participants are female, $45.1 \%$ are between the ages of $40-64,82.7 \%$ are married, $59.6 \%$ unemployed, $40.8 \%$ have associate / undergraduate degree, $46 \%$ had an income between $2001-4000 \mathrm{TL}$ and $98.0 \%$ had social security. $62.4 \%$ of the participants stated that they have a chronic disease and $66.7 \%$ of them use medication. The average of total score of scale was calculated as 35.24 (SS: 12.87). Among the sub-dimensions of the scale, scanning received the highest mean score with 9.76 and verification of diagnosis received the lowest mean score with 5.58 . It was determined that $52.9 \%$ of the participants showed increased abnormal illness behavior. The average scores of scale did not show statistically significant differences according to age groups, gender, marital status, social security status, previous surgery, chronic and psychiatric disease and medication use ( $p>0.05)$. According to the education level of the participants, it was determined that the average score of scale and the expression of symptoms and medication sub-dimensions average score showed statistically significance difference $(\mathrm{p}<0.05)$. It has been determined that individuals with a high school or less education level show increased abnormal illness behavior compared to individuals with bachelor's or higher degree education level. It was determined that the average of total score shows statistically significant difference according to the income level. It has been determined that the difference between the averages is caused by individuals with an income level of 4000TL and below and individuals with an income level of 6001TL and above. Increased abnormal illness behavior is higher in individuals with low income. According to employment status of the participants, it was determined that that the average score of scale and the expression of symptoms and medication sub-dimensions average score showed statistically significance difference $(\mathrm{p}<0.05)$. Unemployed individuals have a 
higher tendency to show increased abnormal illness behavior compared to employed individuals. The illness behavior of individuals directly or indirectly affects their use of health services. In this research, it was determined that the average score of scale show statistically significant difference according to the employment status, income level and education level $(\mathrm{p}<0.05)$. Education affects the working and economic conditions of individuals as well as shapes their health behavior and their tendency to use of health services. Well-educated people are less likely to be unemployed. As the average life expectancy in our country gradually increases, the rate of elderly population is gradually increasing. As the proportion of the elderly population increased, active aging policies started to be developed in every country. While establishing social policies, it is necessary to support activities related to active aging and to develop policies that will give more place to the elderly population in working life.

\section{Kaynakça / References}

Asmundson, G. J. G., Abramowitz, J. S., Richter, A. A. ve Whedon, M. (2010). Health anxiety: Current perspectives and future directions. Current Psychiatry Reports, 12(4), 306-312, 10.1007/s11920-010-0123-9

Coşkun, N. (2017). Kardiyoloji servisinde tedavi gören hastalarda ruh sağhlğı özelliklerinin değerlendirilmesi. Uzmanllk Tezi, Ankara: Gazi Üniversitesi.

Çolak, M. ve Özer, Y. (2015). Sosyal politika anlamında aktif yaşlanma politikalarının ulusal ve yerel düzeydeki analizi. Elektronik Sosyal Bilimler Dergisi, 14 (55), 115124.25.11.2020 tarihinde https://dergipark.org.tr/tr/download/articlefile/70669 adresinden erişildi.

Güleç, H. (2012). Hastalık davranışını değerlendirme ölçeği'nin Türkçe uyarlamasının geçerlilik ve güvenilirliği: Bir ön çalışma. Düşünen Adam Psikiyatri ve Nörolojik Bilimler Dergisi, 25(1), 140-146, 10.5350/DAJPN2012250206

Mechanic, D. ve Volkart, E. (1961). Stress, illness behavior and the sick role. American Sociological Review, 26, 51-58, https://doi.org/10.2307/2090512

Mechanic, D. (1978). Medical sociology. New York: The Free Press.

Mechanic, D. (1995). Sociological dimensions of 1 llness behavior. Social Sciences \& Medicine, 41(9), 1207-1216, https://doi.org/10.1016/0277-9536(95)00025-3

Önder, R. (2014). Sağlkkarama davranışı veetki eden etkenler. Uzmanlkk Tezi, Aydın, Adnan Menderes Üniversitesi. 
Petrie, K.J., Weinmann, J., Sharpe, N. ve Buckley, J. (1996). Role of patients' view of their illness in predicting return to work and functioning after myocardial infarction: longitudinal study. BMJ, 312, 1191-94, 10.1136/bmj.312.7040.1191

Pilowsky, I. (1969). Abnormal 1llness behavior. British Journal of Medical Psychology, 42, https://doi.org/10.1111/j.2044-8341.1969.tb02089.x

Rief, W., Ihle, D., ve Pilger, F. A. (2003). A new approach to assess illness behaviour. J Psychosom Res, 54, 405-414, 10.1016/s0022-3999(02)00401-4

Yılmaz, Ö. (2017). Yetişkinlerde anormal hastalık davranışlan ve yaşam kalitesi ile ilişkili faktörler: Sağhlk kaygısı, kaygı duyarlıı̆̆ı, să̆glkla ilgili işlevsel olmayan inançlar ve aleksitimi. Doktora Tezi, İzmir: Dokuz Eylül Üniversitesi.

Young, J. T. (2004). Illness behaviour: A selective review and synthesis. Sociology of health E illness, 26(1), 1-31, 10.1111/j.1467-9566.2004.00376.x

\section{Kaynakça Bilgisi / Citation Information}

Numanoğlu, R. (2021). Kardiyoloji polikliniğine başvuran hastaların göstermiş oldukları hastalık davranışlarının. OPUS-Uluslararası Toplum Araştırmaları Dergisi, 17(34), 1260-1274. DOI: 10.26466/opus.869338 